\title{
Assessing RV function in patients with Cor pulmonale by using Newer Echocardiographic Parameters
}

Research Article

\author{
A Sarat Kumar Patra, G Rami Reddy, M Shobana, P Arunachalam*
}

Department of Cardiology, Meenakshi Academy of Higher Education and Research, Meenakshi Medical College Hospital and Research Institute, Kanchipuram, Tamil Nadu, India.

\section{Abstract}

\begin{abstract}
Aim: In the present study was investigate that the Newer Echocardiographic parameters in assessing right Ventricular and left ventricular function in patients with Cor Pulmonale. Cor pulmonale is defined as hypertrophy of the right ventricle resulting from diseases resulting from diseases affecting function and /or structure of the lungs, (except when these pulmonary alterations are the result of diseases that primarily affect the left side of the heart such as in congenital cardiac disease). Materials and Methods: A sample size of this study had 40 patients of Cor Pulmonale. Both male and female are selected and there was no age limit in our study population. All patients were assessed Echocardiographic parameters of RV and LV function with Cor Pulmonale.

Results: Right ventricular diastolic dysfunction occurred in about $50 \%$ of the Cor Pulmonale patients. TAPSE of $17 \mathrm{~mm}$ and TASV of $<10 \mathrm{~cm} / \mathrm{sec}$ was taken as having right ventricular systolic dysfunction in our study. The prevalence of TAPSE and TASV calculated right ventricular systolic dysfunction is $95 \%$ and $90 \%$ respectively.

Conclusion: We conclude that TAPSE and TASV were significantly identified Right ventricular systolic dysfunction.
\end{abstract}

Keywords: Right and Left Ventricular, Tricuspid Annular Plane Systolic Excursion; Tricuspid Annular Systolic Velocity.

\section{Introduction}

Pulmonary tuberculosis is prevalent and stays as one of the leading cause of death. The cause of the death in most of the terminally ill pulmonary tuberculosis patient is Cor Pulmonale and related cardiac problem. With the increase in incidence of retro viral infection, diabetes, multi drug resistant pulmonary tuberculosis there is significant increase in the chances for the Cor Pulmonale [1]. In the rural areas poverty and malnutrition lead to increased incidence and prevalence of tuberculosis. In the urban areas exposure to the automobile gases and dust particles predisposes patients to pulmonary diseases and COPD in later life $[2,3]$.

COPD in the later stages lead to right ventricular dilatation and corpulmonale. The development and implementation of the national programs for the detection and treatment of the tuberculosis is trying to treat the disease in the early stage itself to prevent such cor pulmonale in future. In this study we are going to find easy solution to diagnose the lung disease related cardiac problem in the early stages [4].

In Cor Pulmonale patients right ventricular systolic dysfunction is recognized to occur and it has been proved in many studies [5]. But the corpulmonale patients are symptomatic not only because of the lung pathology and right heart failure, but also due to left ventricular dysfunction in the form of left ventricular systolic and left ventricular diastolic dysfunction. The dilated right ventricle pushes the interventricular septum towards left ventricle and interferes with left ventricular filling, which lead onto diastolic dysfunction of left ventricle. The additional metabolic factors like hypoxia, hypercapnea and acidosis lead on to direct myocardial depressant action and produce myocardial dysfunction in both left and right ventricle [6].

In this present study the prevalence of right ventricular systolic, left ventricular systolic and diastolic dysfunction as well as the utility of these simple and newer echocardiographic parameters

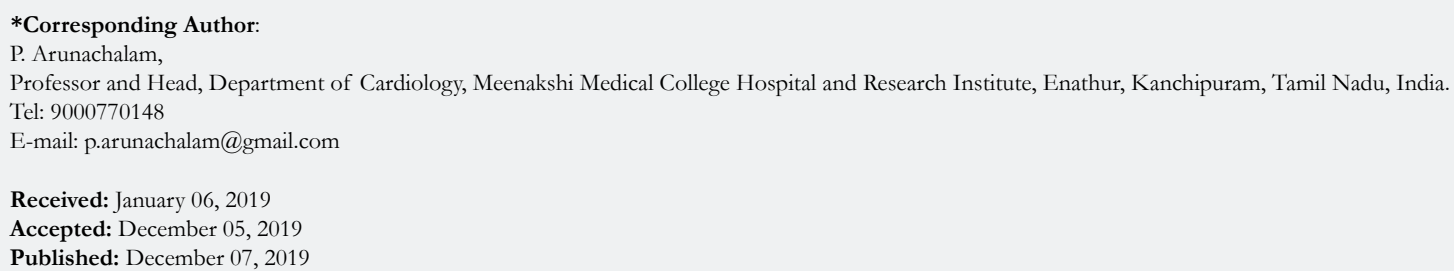

Citation: A Sarat Kumar Patra, G Rami Reddy, M Shobana, P Arunachalam. Assessing RV function in patients with Corpulmonale by using Newer Echocardiographic Parameters. Int J Cardiol Res. 2019;6(3):152-155. doi: http://dx.doi.org/10.19070/2470-4563-1900026

Copyright: P Arunachalam ${ }^{\circ}$ 2019. This is an open-access article distributed under the terms of the Creative Commons Attribution License, which permits unrestricted use, distribution and reproduction in any medium, provided the original author and source are credited. 
in patients with cor pulmonale.

\section{Materials and Methods}

The present study was carried out period from March-2017 to April 2018 in Department of Cardiology, Meenakshi Medical College and Research Institute, Kanchipuram. Ethical clearance was obtained from institution ethical committee. Totally 40 patients of corpulmonale referred for the study of the heart by echocardiography are taken for the study and included. The patients were selected irrespective of the lung pathology that caused corpulmonale. Both male and female patients are selected for the study. There was no age limit in our study population. Patients with acute corpulmonale were not included because of the acute symptoms. Relevant history, clinical examination, $\mathrm{X}$ ray chest, E.C.G was taken for all the patients. Pulse oximetry, pulse rate, systolic and diastolic blood pressure and respiratory rate were taken.

All the patients underwent detailed echocardiographic study. Echocardiogram was done using Philips HD7XE Echocardiographic machine. The following echocardiographic parameters were done. Tricuspid annular plane systolic excursion (TAPSE), Tricuspid annular systolic velocity (TASV), and 'e' propagation velocity and $\mathrm{E} / \mathrm{A}$ ratio were taken. TAPSE $<17 \mathrm{~mm}$ and 'e' propagation velocity $<50 \mathrm{~cm} / \mathrm{s}$ were taken as cut-offs for abnormal values as per American Society of Echocardiography recommendations. Pulmonary hypertension was graded as mild, moderate and severe based on the tricuspid regurgitation pressure gradient on the echocardiography.

\section{Results}

40 patients of established cor pulmonale were selected for the study. Among them 23 were males and 17 were females. All are having right ventricular enlargement due to lung pathology.
Among them 30 patients have COPD, 8 patients have old pulmonary tuberculosis and 2 patients have interstitial lung disease. The COPD comprises of $75 \%$ of study population; $20 \%$ of cases are old pulmonary tuberculosis and $5 \%$ of cases are interstitial lung disease patients. Age of the patients ranged from 29 years to 70 years with the mean value of age is 49.5 years. Among female patients age range from 29 years to 68 years with the mean age of 48.5 years. For the male patients it ranged from 29 years to 70 years with mean age of 49.5 years (Table 1 ).

Among the male patients corpulmonale is more common in the age group between 30-60 years of age .corpulmonale is less common before 30 years of age in both males and females. In female gender high prevalence was noted between $50-60$ years of age. In the age group of 60-70 years corpulmonale is slightly higher in the females when compared to males.

Among these 40 patients 18 patients had mild pulmonary hypertension, 8 patients had moderate pulmonary hypertension and 14 patients had severe pulmonary hypertension. These comprises of $45 \%$ of patients with mild pulmonary hypertension, $20 \%$ of patients with moderate pulmonary hypertension and $35 \%$ of patients with severe pulmonary hypertension (Table 2).

The prevalence of mild pulmonary hypertension is more in females. The severe pulmonary hypertension prevalence is more in the males. This severe pulmonary hypertension being more common in males is probably due to increased smoking in the males. In the study population also males are more commonly affected than the females because of the same reason.

\section{TAPSE in Right Ventricular Systolic dysfunction}

Figure 1. Shows that the TAPSE of $<17 \mathrm{~mm}$ was taken as having right ventricular systolic dysfunction in our study. 38 out of 40 patients had TAPSE of $<17 \mathrm{MM}$. so prevalence of TAPSE calculated right ventricular systolic dysfunction is $95 \%$ in our

Table 1. Age and Sex distribution of Study Population.

\begin{tabular}{|c|c|c|c|c|c|c|}
\hline \multirow{2}{*}{$\begin{array}{c}\text { Age } \\
\text { Group }\end{array}$} & \multicolumn{2}{|c|}{ Male } & \multicolumn{2}{c|}{ Female } & \multicolumn{2}{c|}{ Total } \\
\cline { 2 - 7 } & No of Patients & Percentage & No of Patients & Percentage & No of Patients & Percentage \\
\hline$<30$ & 1 & 4.3 & 1 & 5.9 & 2 & 5 \\
\hline $31-40$ & 6 & 26.1 & 4 & 23.5 & 10 & 25 \\
\hline $41-50$ & 6 & 26.1 & 4 & 23.5 & 10 & 25 \\
\hline $51-60$ & 6 & 26.1 & 6 & 35.3 & 12 & 30 \\
\hline $61-70$ & 4 & 17.4 & 2 & 11.8 & 6 & 15 \\
\hline Total & 23 & 100 & 17 & 100 & 40 & 100 \\
\hline Mean \pm SD & \multicolumn{2}{|c|}{$49.0 \pm 11.38$} & $49.52 \pm 10.9$ & $49.22 \pm 11.04$ \\
\hline
\end{tabular}

Table 2. Severity of Pulmonary Hypertension.

\begin{tabular}{|c|c|c|c|c|c|c|}
\hline \multirow{2}{*}{$\begin{array}{c}\text { Pulmonary } \\
\text { Hypertension }\end{array}$} & \multicolumn{2}{|c|}{ Male } & \multicolumn{2}{c|}{ Female } & \multicolumn{2}{c|}{ Total } \\
\cline { 2 - 7 } & No of Patient & Percentage & No of patients & Percentage & No of Patients & Percentage \\
\hline Mild & 9 & 39.13 & 9 & 52.94 & 18 & 45 \\
\hline Moderate & 5 & 21.74 & 3 & 17.64 & 8 & 20 \\
\hline Severe & 9 & 39.13 & 5 & 29.42 & 14 & 35 \\
\hline Total & 23 & 100 & 17 & 100 & 40 & 100 \\
\hline
\end{tabular}


study. $5 \%$ of patients were not having right ventricular systolic dysfunction when TAPSE was taken as the echocardiographic parameter.

\section{TASV in Right Ventricular Systolic dysfunction}

Figure 2. indicated that the TASV of $<10 \mathrm{~cm} / \mathrm{sec}$ was taken as having right ventricular systolic dysfunction in our study. 36 out of 40 patients had TASV of $<10 \mathrm{~cm} / \mathrm{sec}$. so prevalence of TASV calculated right ventricular systolic dysfunction is $90 \%$ in our study. $10 \%$ of patients were not having right ventricular systolic dysfunction when TASV was taken as the parameter.

Prevalence of RV systolic dysfunction using TAPSE and TASV

Figure 3. showed that TAPSE and TASV are more reliable Parameters. Both of them correlate well with the right ventricular systolic dysfunction. Their sensitivity and specificity in identifying the problem was very high. They can detect even subtle problem which other parameters cannot do reliably. These simple parameters are proved useful in the acute set up also like right ventricular infarction in various studies.

TAPSE assess longitudinal right ventricular systolic dysfunction and its calculation detects many patients with early systolic dysfunction. But left ventricular systolic dysfunction which occur very late in the course of the disease is not that common when compared to right ventricular systolic dysfunction. These two parameters are derived from m-mode echocardiography.

\section{Discussion}

This study was undertaken to establish the role of simple and useful parameters like TAPSE and TASV in patients with corpulmonale. Also in this study we aimed to study the

Figure 1. TAPSE (tricuspid annular plane systolic exertion)

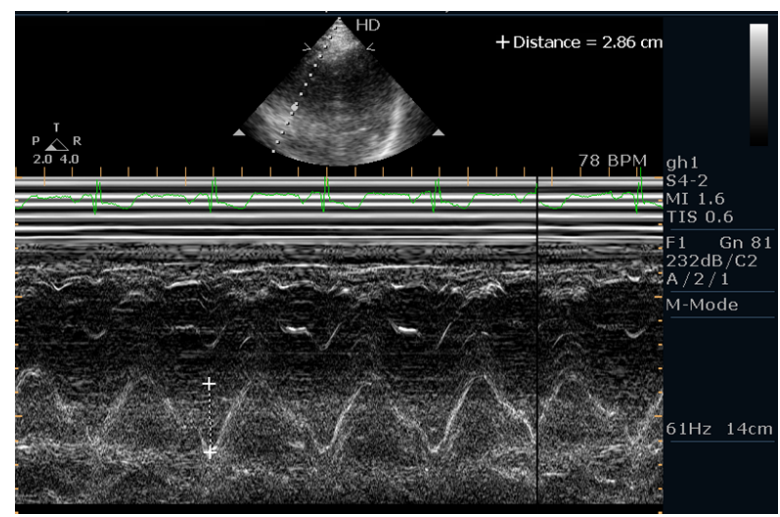

Figure 2. TASV (tricuspid annular systolic velocity).

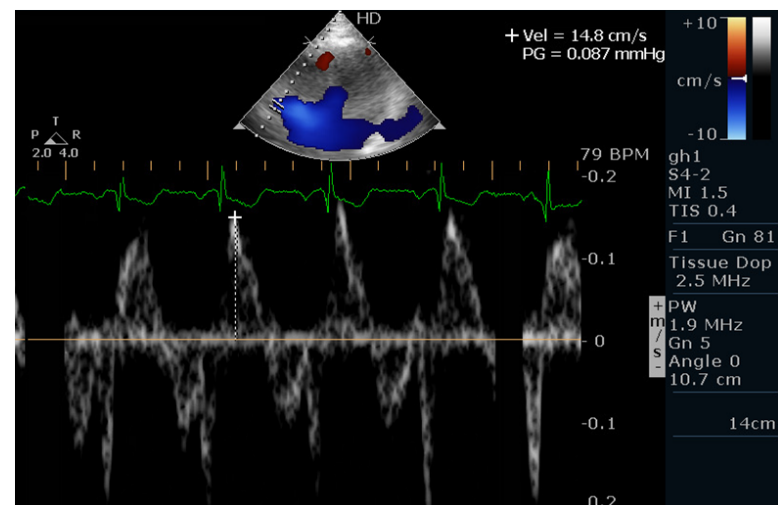

Figure 3. Prevalence of RV systolic dysfunction using TAPSE and TASV.

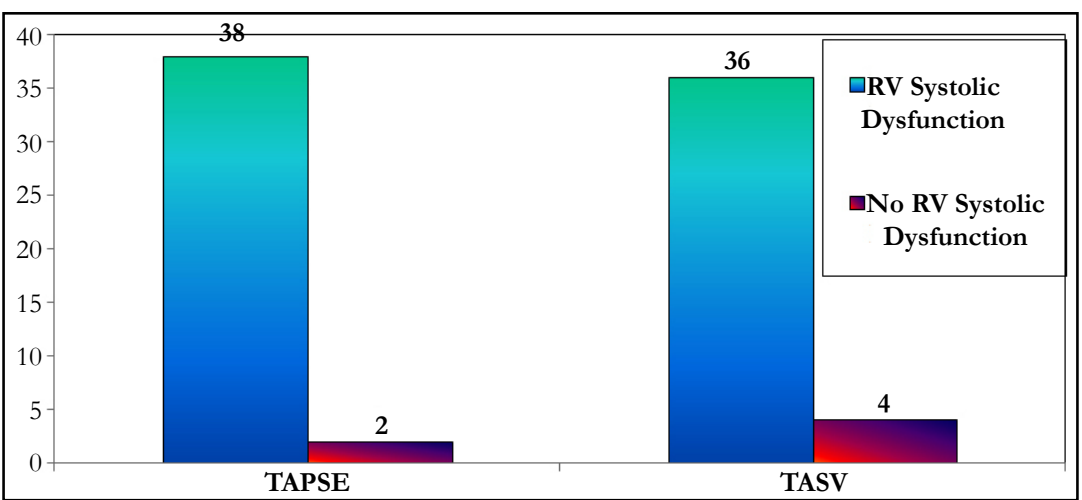


prevalence of left ventricular systolic and diastolic dysfunction in corpulmonale cases.

TAPSE is a simple method when compared to RVEF and RV TEI index for studying right ventricular systolic dysfunction .It reliably detects right ventricular systolic dysfunction and the value decreased as the severity of systolic dysfunction worsen. Right ventricular systolic dysfunction was very much in patients with severe pulmonary hypertension when compared to mild pulmonary hypertension [7].

In another Swiss study published in 2005 the tricuspid annulus systolic velocity of lateral annulus $>12 \mathrm{~cm} / \mathrm{sec}$ identified normal systolic function with right ventricular ejection fraction of $>55 \%$. TASV $<9 \mathrm{~cm} / \mathrm{sec}$ in patients with right ventricular dysfunction was able to identify the problem correctly and right ventricular ejection fraction in this patients were between 30-55\% [8].

TASV is another newer parameter which utilizes tissue Doppler to assess the right ventricular systolic dysfunction. The value of $<10 \mathrm{~cm} / \mathrm{sec}$ was taken as the cut off value. It correlated well with the TAPSE in identifying the right ventricular systolic dysfunction. It is well known that diseases like chronic bronchitis, pulmonary tuberculosis, emphysema, bronchial asthma, interstitial lung diseases and occupational diseases cause cor pulmonale. But in our study COPD, pulmonary tuberculosis and interstitial lung diseases were the diseases that caused the cor pulmonale [9].

In tuberculosis cause for the development of the cor pulmonale include decrease in the lung elasticity, parenchymal disease, and decrease in the diffusion capacity of the lung, obstruction of the bronchioles due to brochospasm and destruction of the lung tissue. Development of the cor pulmonale leads to terminal stage of the disease process and patient may go for congestive cardiac failure [10].

\section{Conclusion}

In the present study conclude that the TAPSE and TASV were significantly identified Right ventricular systolic dysfunction. TAPSE and TASV are simple and useful index in corpulmonale patients to assess right ventricular systolic dysfunction. It is found that atleast some amount of right ventricular systolic dysfunction was detected when the newer echocardiographic parameters were used in most of the cor pulmonale patients.

\section{References}

[1]. Murray CJ, Lopez AD. Evidence based health policy-lessons from the Global Burden of disease Study. Science 1996; 274:740-3. PMID: 8966556.

[2]. World Health Report. Geneva: World Health Organization; 2000. Available from: http://www.who.int/whr/2000/en/statistics.htm. [Last accessed on $2004 \mathrm{Jan}]$.

[3]. Anthonisen NR, Connett JE, Kiley JP, Altose MD, Bailey WC, Buist AS, et al., Effects of Smoking Intervention and the Use of an Inhaled Anticholinergic Bronchodilator on the Rate of Decline of FEV1. JAMA 1994; 272:1497-1505.

[4]. Sin DD, Anthonisen NR, Soriano JB, Agusti AG. Mortality in COPD: Role of comorbidities. Eur Respir J. 2006; 28: 1245-57. PMID: 17138679.

[5]. Daniels LB, Krummen DE, Blanchard DG. Echocardiography in pulmonary vascular disease. Cardiol Clin. 2004; 22: 383-99. PMID: 15302359.

[6]. Yock PG, Popp RL. Noninvasive estimation of right ventricular systolic pressure by Doppler ultrasound in patients with tricuspid regurgitation. Circulation. 1984; 70: 657-62. PMID: 6478568.

[7]. Tramarin R, Torbicki A, Marchandise B, Laaban JP, Morpurgo M. Doppler echocardiographic evaluation of pulmonary artery pressure in chronic obstructive pulmonary disease. A European multicentre study. Working Group on Noninvasive Evaluation of Pulmonary Artery Pressure. European Office of the World Health Organization, Copenhagen. Eur Heart J. 1991; 12: 103-1. PMID: 2044542.

[8]. Chaouat A, Bugnet AS, Kadaoui N, Schott R, Enache I, Ducoloné A, et al. Severe pulmonary hypertension and chronic obstructive pulmonary disease. Am J Respire Care Med 2005; 172:189-94. PMID: 15831842.

[9]. Thabut G, Dauriat G, Stern JB, Logeart D, Lévy A, Marrash- Chahla R, et al. Pulmonary Haemodynamics in advanced COPD candidate for lung volume eduction surgery or lung transplantation. Chest 2005;127:1531-6. PMID: 15888824.

[10]. Rappaport E. Cor pulmonale. 4th ed. In: Murray JJ, Nadel JA, Mason RM, Boushey H, editors. Textbook of respiratory medicine. Philadelphia, W.B. Saunders. 2000; 1631-48. 